\title{
“ÉTUDE SUR L'HUMOUR”: CHARLES LAMB NA BIBLIOTECA DE MACHADO DE ASSIS
}

\section{DANIEL LAGO MONTEIRO}

Universidade Estadual de Campinas

Campinas, São Paulo, Brasil

Resumo: O presente artigo se propõe a investigar a edição francesa de Charles Lamb, Essais Choisis, que Machado de Assis possuía em sua biblioteca. Esta edição foi publicada em 1880, no mesmo ano em que Machado inicia as Memórias póstumas de Brás Cubas na Revista Brasileira, e contava com um extenso aparato crítico, "Étude sur L'humour", no qual o tradutor, Louis Dépret, investiga as bases filosóficas e literárias do humor inglês e da obra de Lamb. Assim, neste artigo, faremos uma análise filosófica e filológica dos termos associados ao humor discutidos no prefácio de Dépret, por meio do qual esperamos aprofundar o conhecimento que Machado possuía do humorismo e ensaísmo de Lamb.

Palavras-chave: Charles Lamb; Machado de Assis; Biblioteca de Machado; Humor; Ensaísmo.

\section{“ÉTUDE SUR L'HUMOUR”: CHARLES LAMB IN MACHADO DE ASSIS'S LIBRARY}

\begin{abstract}
This article aims to investigate Charles Lamb's French publication, Essais Choisis, a copy of which Machado de Assis kept in his library. This book was published in 1880, the same year Machado began writing Memórias póstumas de Brás Cubas in Revista Brasileira, and includes an extensive critical study, "Étude sur L'humour", in which the translator, Louis Dépret, investigates the philosophical and literary grounds of English humour and of Lamb's work. Thus, in this paper, I will conduct a philosophical and philological analysis of the terms associated with humour as discussed in Dépret's preface, by which I hope to deepen the knowledge Machado had of Lamb's humourism and essay writing.
\end{abstract}


Keywords: Charles Lamb; Machado de Assis; Machado's Library; Humor; Essay writing.

A Luís Fernandes dos Santos Nascimento, a pessoa mais witty que já conheci.

1

primeira edição em livro das Memórias póstumas de Brás Cubas (1881) contava com duas novidades inexistentes na versão seriada que apareceu na Revista Brasileira de 15 março a 15 dezembro de 1880: a dedicatória “Ao verme" e a nota "Ao leitor". Esta última apresenta a um só tempo uma definição de estilo, forma e sentimento que o leitor encontrará no livro - "obra difusa", "forma livre", escrita "com a pena da galhofa e a tinta da melancolia" - e da linhagem de escritores à qual Brás Cubas reivindica pertencimento. Assim, lemos na primeira edição: "adotei a forma livre de um Sterne, de um Lamb, ou de um Maistre” (ASSIS, 1881, p. v). As referências anglófonas, Sterne e Lamb, ao lado das cambalhotas narrativas, da ironia discreta, da prosa fragmentada, do humor à inglesa, entre outros elementos, produziram certo ruído na crítica de seu tempo, porque em tudo distintos dos modelos franceses e das convenções narrativas então em curso no Brasil, como observa Hélio de Seixas Guimarães. Em “Ao leitor”, continua Guimarães, Machado procura se explicar aos críticos de sua geração, confirmando a suspeita, levantada por Artur Barreiros, por exemplo, de que sim, o autor incorporou o humorismo inglês à sua prosa. (GUIMARÃES, 2017, p. 55). Nas edições seguintes das Memórias póstumas, o nome de Lamb desapareceu.

Por muito tempo, a crítica machadiana ignorou a supressão intencional ou não do nome de Lamb. Salvo engano, foi Sergio Paulo Rouanet, em Riso e melancolia, quem mais se demorou no assunto. Ali o autor desenvolve o argumento de que Laurence Sterne, em Tristram Shandy, haveria formulado as características de sua narrativa e de que essas seriam as bases para uma linhagem que inclui, além de Machado, Diderot, Xavier de Maistre e Almeida Garrett. Ao final do primeiro capítulo de Riso e melancolia, Rouanet lembra que o nome de Lamb consta do prólogo da primeira edição das Memórias póstumas, que Machado possuía um exemplar da obra de Lamb em francês, mas que ele teve "razão" em excluir o nome de Lamb, pois o humor não basta para definir a forma shandiana, a qual, segundo Rouanet, envolve quatro características básicas: hipertrofia da subjetividade; digressividade e 
fragmentação; subjetivação do espaço e do tempo; interpenetração de riso e melancolia (ROUANET, 2007, p. 31-33 e 244).

Se não teremos espaço aqui para analisar trecho a trecho a presença ou não dessas características na principal obra de Lamb, Ensaios de Elia, tema que mereceria um estudo à parte, pretendo neste artigo ressaltar que o humor e o ensaio, tais quais compreendidos e praticados por Lamb, distinguem-se pela ambivalência entre riso e melancolia. No meu entendimento, essas questões se esclarecem a partir de um exame da edição francesa de Lamb que Machado possuía em sua biblioteca.

Em 1880, foi publicado em Paris, pela editora G. Charpentier, LibraireÉditeur, o livro Essais Choisis, de Lamb, com tradução e prefácio de Louis Dépret (1837-1901). Machado adquiriu um exemplar do livro na Livraria Garnier (JOBIM, 2001, p. 219). Não sabemos ao certo o mês da publicação, ${ }^{1}$ tampouco da aquisição. Contudo, como observou o crítico norte-americano Benjamin Mather Woodbridge Jr., há indícios de que Machado teve contato com a obra de Lamb em inglês e no momento em que preparava as Memórias na Revista Brasileira. ${ }^{2}$ Seja como for, a obra Essais Choisis é por si só significativa, tanto pelos ensaios ali reunidos quanto pelo prefácio e apêndice. O prefácio, um texto de 125 páginas, é dividido em duas partes: "Étude sur L'humour" e "Notice Biographique et Littéraire sur Charles Lamb". O apêndice inclui os textos: "Mémoire Biographique sur Charles Lamb" (de John Forster, amigo íntimo e biógrafo de Charles Dickens), "De L'Esprit e de L'Humour”, “Addison” (perfil do autor, incluindo a tradução de um ensaio do The Spectator) e "M. Charles Kent" (outro íntimo de Dickens e "a quem devemos a edição centenária das obras de Lamb”) (DÉPRET, 1880, p. 437). ${ }^{3}$

Comecemos comparando a seleção de Essais Choisis com a estrutura da terceira ediçãa em livro dos Ensaios de Elia (1835). Esta edição, que serviu de base para as publicações subsequentes, inclui os Últimos ensaios de Elia, que também apareceram inicialmente em forma seriada, e, em alguns casos, "Confissões de um beberrão". Nas imagens a seguir, temos uma reprodução de seus respectivos sumários:

\footnotetext{
${ }^{1}$ Tudo indica que Essais Choisis foi publicado em meados daquele ano, pois Journal des Débats publicou uma resenha do livro no dia 19 de julho de 1880. Fonte: <gallica.bnf.fr> Bibliothèque Nationale de France. Agradeço a Jéssica Cristina Jardim por chamar minha atenção para essa fonte.

${ }^{2}$ Segundo Woodbridge Jr., no capítulo CXXXV das Memorias póstumas, o autor cita uma passagem de Christian Morals, de sir Thomas Browne, que ele colheu do ensaio "My Relations" de Lamb, pois dele preservou o versalete: oblivion. Nas palavras de Woodbridge Jr.: “[...] em nenhuma das edições de Christian Morals que tive oportunidade de consultar, a palavra 'oblivion' está escrita em maiúsculas" (WOODBRIDGE JR., 2014, p. 4). Vale ressaltar que na edição de Dépret o termo aparece como Oubli, sem o versalete (LAMB, 1880, p. 261).

${ }^{3}$ As traduções do francês contaram com a revisão de Marina Yajima, a quem sou grato.
} 
Machado de Assis em Linha - Universidade de São Paulo

http://machadodeassis.fflch.usp.br - Artigo

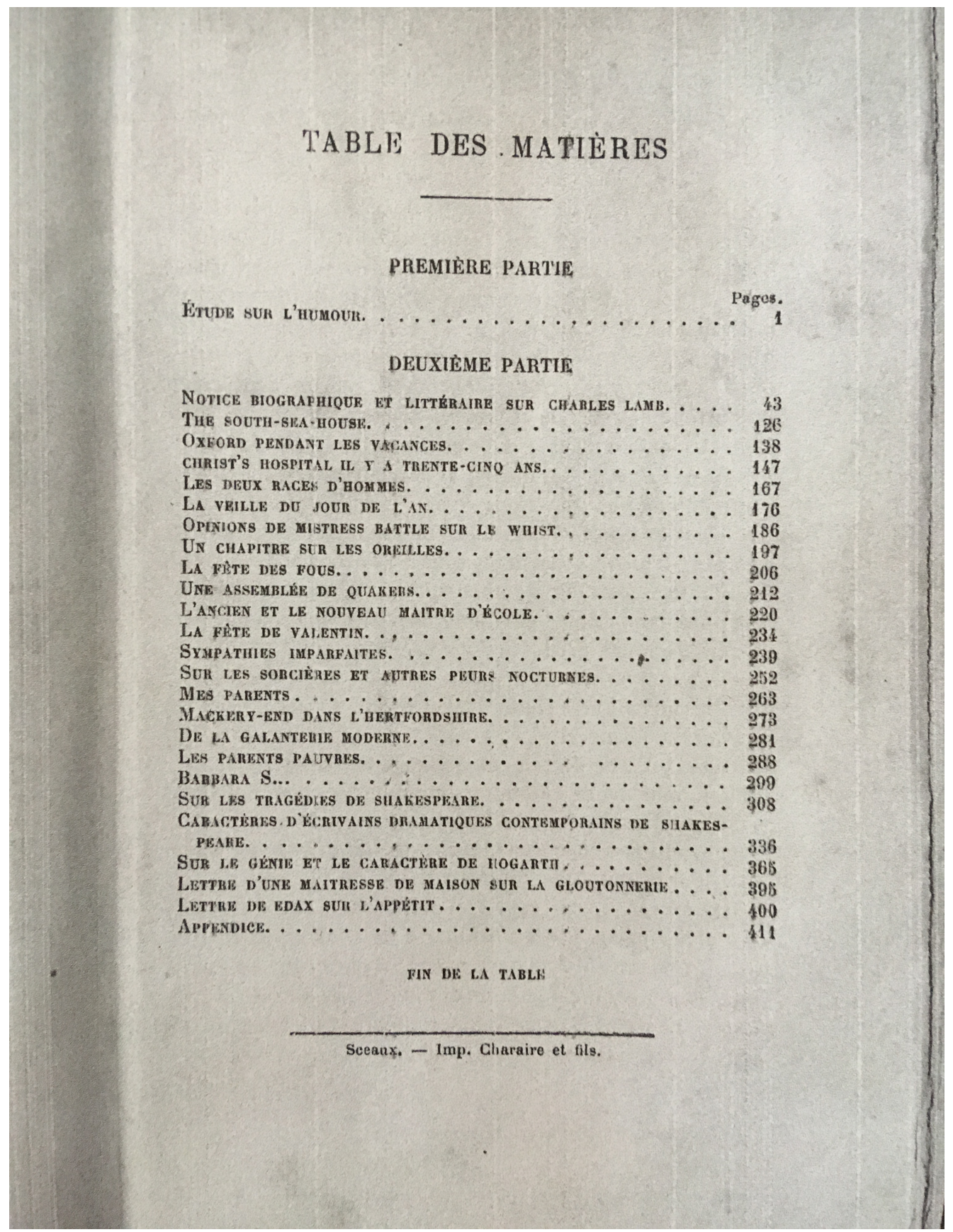

Figura 1: Reprodução do sumário de Essais Choisis (1880) 
Machado de Assis em Linha - Universidade de São Paulo

http://machadodeassis.fflch.usp.br - Artigo

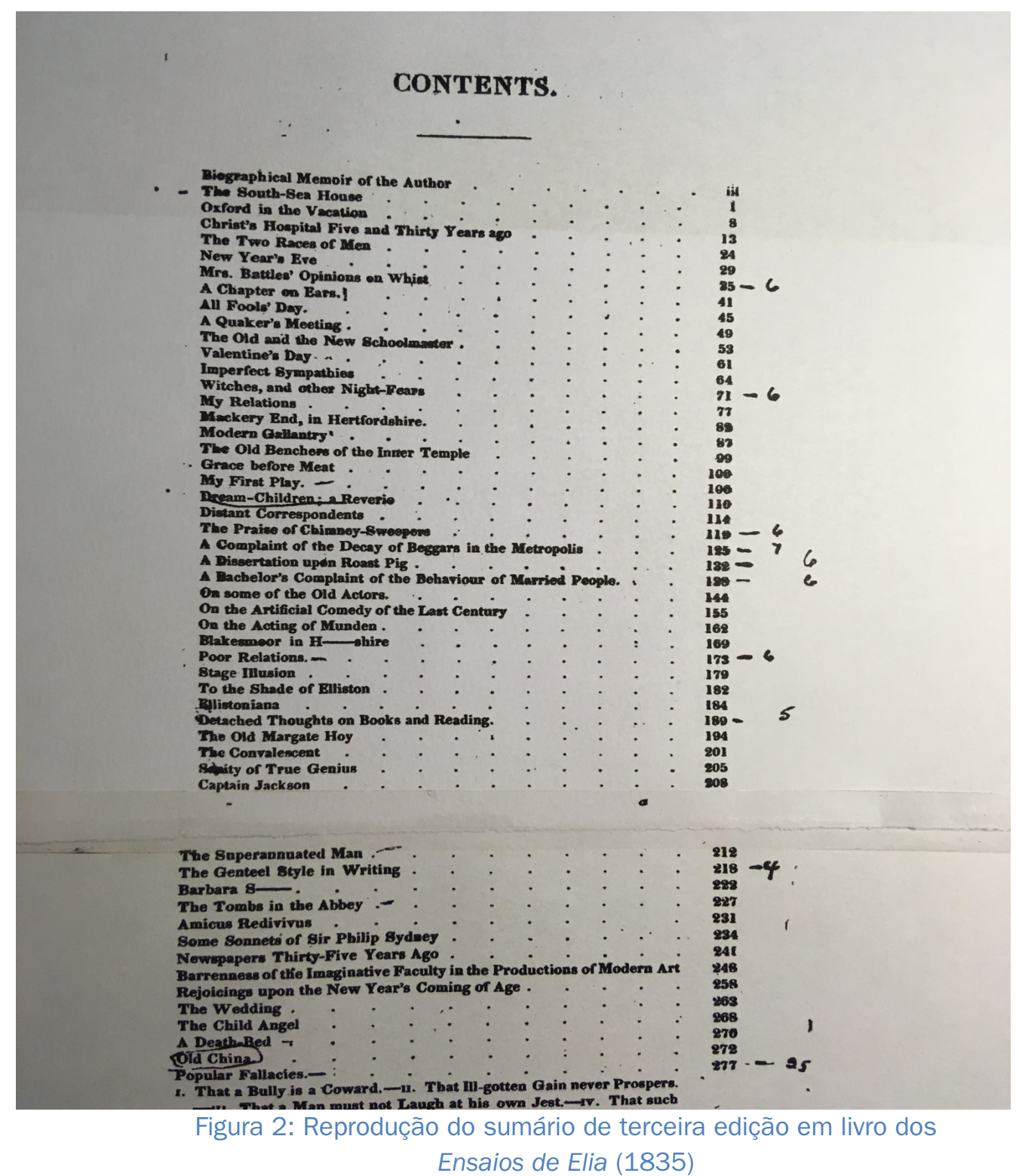

Como se nota, Essais Choisis inclui sequencialmente os dezesseis primeiros Ensaios de Elia, dois dos Últimos ensaios de Elia e cinco outros ensaios, entre eles, alguns dos escritos críticos mais conhecidos do autor: "On the Tragedies of Shakespeare" e "On the Genius and Character of Hogarth". A edição em livro preparada por Lamb em 1833, que traz os Últimos ensaios de Elia precedidos de um prefácio ficcional, deve ser lida na íntegra e na ordem para que se tenha uma visão completa da sua história de vida. Essais Choisis não nos permite essa compreensão. No entanto, o extenso estudo desenvolvido pelo tradutor, Dépret, pode lançar luz sobre as formas de humor presentes tanto nos Ensaios de Elia quanto nas Memórias póstumas. Falemos, 
portanto, mais detidamente, do amplo aparato crítico de Essais Choisis, sobretudo de sua parte mais volumosa, "Étude sur L'humour".

Em 1880, Dépret - poeta, romancista, dramaturgo e crítico - era um respeitado divulgador da literatura de língua inglesa na França. Suas publicações incluem estudos sobre Dickens, Longfellow, Wilkie Collins, Lorde Byron, Shakespeare e, notavelmente, Lamb. No prefácio a Essais Choisis, Dépret recorre aos principais críticos ingleses de seu tempo para traçar, inicialmente, um perfil de Lamb bem ao sabor do século; isto é, a imagem de um autor dócil e de bom coração. É ela que encontramos no ensaio de Lorde Macaulay, citado por Dépret: “Admiramos seu gênio e admiramos a bondade de seu coração, que aparece em todos os seus escritos" (DÉPRET, 1880, p. 5); em "Mémoire Biographique sur Charles Lamb", de Forster: "Ele foi a pessoa mais amável que jamais conhecemos" (DÉPRET, 1880, p. 420); e, por fim, na canonização do autor, na década de 1870, expressa na conhecida passagem de William Thackeray: “Saint Charles!" (RIEHL, 1998, p. 52). Entretanto, Dépret parece oscilar em seu perfil de Lamb: entre o dócil e afável e o espirituoso e irônico. Em suas palavras, Lamb foi "um sujeito amável porém picante" (DÉPRET, 1880, p. 6). Ao acentuar esse temperamento agridoce, Dépret traz o humor para o centro das atenções. Lamb é descrito como o típico humorista inglês.

O humor é, como se sabe, um dos temas fulcrais do romantismo, tanto em sua vertente inglesa quanto na alemã. Contudo, lembra Dépret, a história e filosofia da palavra é anterior, designa tanto um traço de caráter quanto um modo de literatura e não consiste em monopólio desta ou daquela nação. $\mathrm{Na}$ França, diz o crítico, foram humoristas Rabelais, Montaigne, La Fontaine, Pascal e Xavier de Maistre; na Espanha, Cervantes; na Itália, Boccaccio; na Alemanha, Jean Paul Richter e Heinrich Heine. Ainda assim, diz Dépret: “A verdade é que essa nação [Inglaterra] produziu muitos humoristas e que ela foi a primeira [...] preocupada em determinar as condições e a utilidade social do humor". Além disso, continua Dépret, os ingleses acentuaram um tipo específico de humor: "a ideia da passagem brusca da alegria sensual às sombras fastidiosas da vida interior" (DÉPRET, 1880, p. 9-10). Essa disposição contraditória ou mesmo paradoxal está na base tanto da definição de humor que Dépret persegue quanto do perfil que traça de Lamb.

Em sentido estrito, humour se define pela mistura de riso e melancolia. Poder-se-ia até mesmo dizer que o efeito cômico provém dessa junção; isto é, da capacidade de rir de si mesmo, de suas desgraças e dos absurdos do mundo. O tema ocupa algumas páginas de "Étude sur L'humour", que retoma suas 
bases filosóficas e cujas principais fontes são Addison, History of English humour, de A.G. L'Estrange (um clássico da era vitoriana), e intérpretes franceses. À maneira de Dépret, façamos um sobrevoo sobre alguns conceitoschave do humor inglês.

A teoria de Addison se apoia no par wit e humour, inseparável na filosofia e literatura inglesas do século XVII ao XIX. Termo difícil de se traduzir, wit corresponde tanto a uma faculdade da mente, a faculdade do engenho, pelo seu caráter inventivo, quanto aos produtos dessa faculdade: chistes, ditos espirituosos, metáforas ou comparações em geral. Addison distingue o verdadeiro do falso wit, bem como o verdadeiro do falso humour. Antes de falarmos dessas distinções convém um recuo a uma outra.

Enquanto talento ou faculdade da mente, engenho [wit] se compreende na sua relação com o juízo [judgement]. Uma das primeiras reflexões sobre wit e judgement se encontra precisamente no livro que inaugura a tradição ensaística na Inglaterra, Essays, de Francis Bacon. O ensaio "Of Discourse" [Sobre a conversação] se abre da seguinte forma: "Some in their discourse desire rather commendation of wit, in being able to hold all arguments, than of judgment, in discerning what is true" (BACON, 2008, p. 102, grifo nosso). Wit é, pois, aquela faculdade ou talento de sustentar todos os argumentos; judgement, de distinguir o certo do errado. Na continuação do ensaio, aqueles que dominam a arte da conversação são capazes de combinar engenho e juízo, de passar da piada à seriedade. A disposição séria permite que se siga uma linha argumentativa; a piadista a um só tempo reúne os argumentos e introduz a diversão, também no sentido de divergir, ao misturar anedotas e perguntas aos temas tratados. Wit é o sal da conversa, diz Bacon. O excesso de wit, por sua vez, a torna amarga: só se responde uma tirada espirituosa com outra. $\mathrm{Ou}$ ainda, noutros termos, sem a devida mistura de engenho e juízo a conversa se torna tediosa. São alguns os sinônimos de tédio no ensaio - dull, jade, wearisome etc. -, o que parece sugerir que o cultivo da boa conversa inibe o tédio, uma das chagas do verdadeiro humorista: poderíamos nos referir ao mundo de cortinas corridas de Elia ou à flor amarela de Brás Cubas.

Entretanto, foi sobretudo com John Locke que engenho e juízo ganharam seus contornos filosóficos. "Engenho", diz Locke, "consiste principalmente em congregar ideias [...] minimamente semelhantes ou congruentes" (LOCKE, 2012, p. 155-156); juízo, "em cuidadosamente separar ideias minimamente diferentes” (DÉPRET, 1880, p. 16-17).

Como em Bacon, engenho reúne, juízo separa. Ambos são processos mentais ou talentos que consistem em atentar para as mais diminutas 
semelhanças ou diferenças entre as ideias. $\mathrm{O}$ engenho põe em relação ideias que a princípio não se relacionam entre si; o juízo mostra as diferenças entre ideias semelhantes. Segundo Locke, para o bem do conhecimento claro e distinto e para melhor articular as ideias que compõem o significado de um termo, o engenho deve se dobrar ao juízo. Isto porque, continua ele, é raro encontrar engenho e juízo juntos na mesma pessoa. Brás Cubas, com sua usual busca por superioridade, declara estar de posse de ambas faculdades ou talentos: "Grande coisa é haver recebido do céu uma partícula da sabedoria, o dom de achar as relações das coisas, a faculdade de as comparar e o talento de concluir! Eu tive essa distinção psíquica” (ASSIS, 2015, p. 713). O trecho se encontra no tomo VI, $1^{\circ}$ de novembro, da Revista Brasileira, o mesmo no qual o autor incluiu a citação de sir Thomas Browne colhida de Lamb, como bem observou Woodbridge Jr. Ainda que não possamos saber se Machado estava de posse de Essais Choisis naquele momento, não nos parece improvável que essa tenha sido uma de suas fontes. ${ }^{4}$ Brás Cubas, personagem e narrador, pode recorrer a essas distinções em sentido paródico, como frequentemente o faz o narrador de Tristram Shandy. Contudo, a atividade de pôr juntas ideias dessemelhantes e, com isso, produzir um efeito surpreendente ou mesmo cômico é uma técnica recorrente nas Memórias póstumas, em Tristram Shandy e nos Ensaios de Elia. Noutras palavras, wit também corresponde a um certo uso da linguagem, tema ao qual se volta o ensaio de Addison.

Neste ensaio do The Spectator de 11 de maio de 1711, ele diz: “[...] nem toda semelhança de ideias chamamos de wit, exceto aquelas que produzem deleite ou surpresa no leitor" (ADDISON; STEELE, 1982, p. 345, grifo nosso). Locke já havia atentado para os efeitos prazenteiros que wit produz na fantasia e sua relação com as figuras de linguagem. A novidade de Addison foi ter colocado a experiência do leitor e a literatura em primeiro plano. São espécies de wit, segundo ele: “[...] metáforas, similitudes, alegorias, enigmas, máximas, parábolas, fábulas, sonhos, visões, escritas dramáticas, o burlesco e todo método de alusão" (ADDISON; STEELE, 1982, p. 345). Em suma, toda produção literária é uma manifestação do engenho. Se não há literatura sem engenho, a boa ou má literatura se define pelo seu uso. Addison classifica de engenho verdadeiro as semelhanças e congruências de ideias; de engenho falso, quando essas se reduzem a letras do alfabeto, a sílabas ou a palavras. Há ainda uma terceira espécie, uma combinação das duas, mixt wit, ou seja, quando ocorre a um só tempo uma semelhança entre ideias e palavras. Essa

${ }^{4}$ Em pesquisa realizada na biblioteca de Machado de Assis, não encontramos nenhum registro de leitura. Contudo, como observa Jean-Michel Massa, "[Machado] não anotava nos livros que lia. No máximo algumas linhas inocentes nas páginas de grade de algumas obras" (JOBIM, 2001, p. 25). 
espécie de wit se revela, sobretudo, em epigramas: “[...] ou naqueles pequenos poemas ocasionais que em suas naturezas não passam de um tecido de epigramas" (ADDISON; STEELE, 1982, p. 345). Em linhagem direta com essa tradição, "epigramas e aforismos, a moeda de troca dos antigos ensaístas, estão presentes abundantemente em Lamb” (MACDONALD, 1917, p. 560). De fato, todas as formas de wit elencadas por Addison recheiam os Ensaios de Elia, mesmo aquelas pertencentes ao falso wit, a começar pelo nome anagramático (Elia - a lie) e sua defesa de que "os piores trocadilhos são os melhores" (LAMB, 1987, p. 292).

Também as Memórias póstumas se valem de trocadilhos de mau gosto. Um deles guarda uma referência explícita a Lamb. No capítulo LXIX, "Um grão de sandice”, diz Brás Cubas: “[...] tomei tanto tártaro, tanto tártaro, tanto tártaro, que fiquei Tártaro” (ASSIS, 2015, p. 670). O mesmo chiste um tanto pueril aparece em uma das famosas cartas de Lamb, muitas das quais eram assinadas por Elia. Em correspondência com o amigo, Manning, que rumava ao Oriente e se encontrava entre "o povo tártaro", o autor concebe "um sujeito tártaro comendo meu amigo e acrescentando uma malignidade fria de mostarda e vinagre" (apud HIGGINS, 2014, p. 153). Assim como em Machado, o excesso de wit, em Lamb, confere a sua prosa um ar de pedantismo e deboche. Seria essa uma busca por uma superioridade, qualquer que fosse (SCHWARZ, 2000, p. 63-83), como encontramos em Brás Cubas? Em certo sentido, sim. Mas, poderíamos dizer, trata-se de uma superioridade invertida, que se orgulha de carecer daquilo que os demais possuem. Dos inúmeros exemplos que poderíamos citar, fiquemos com essa passagem de "A Chapter on Ears”, no qual o autor joga com o duplo sentido da palavra, enquanto órgão de audição e certa habilidade para música, produzindo, assim, um efeito surpreendente e cômico:

Não tenho ouvido. -

Não me entenda mal, leitor, - tampouco imagine que, por natureza, sou destituído daqueles acessórios gêmeos exteriores, aqueles ornamentos dependurados e (em termos arquitetônicos) aquelas belas volutas do capitólio humano. Melhor seria se minha mãe não tivesse me concebido -. Sou, imagino, provido delicada e copiosamente dessas tubulações; não sinto qualquer disposição para invejar a mula pela sua abundância, ou a toupeira pela sua estreiteza, com aquelas aberturas labirínticas - aqueles agentes secretos, duplos e indispensáveis [...]. 
Quando digo que não tenho ouvido, você saberá a que me refiro - para música. (LAMB, 1987, p. 43-44, grifo do autor) ${ }^{5}$

Passemos à segunda distinção proposta por Addison e exposta em “Étude sur L'humour”, de Dépret, entre o verdadeiro e o falso humour. Ali, Addison nos conta uma história alegórica dos diferentes tipos de humor, cujas linhas mestras reproduziremos a seguir.

Se o humor fosse personificado, quais seriam seu caráter e sua genealogia? O verdadeiro Humor, naturalmente, descende da Verdade. Verdade (Truth) é o patriarca de uma linhagem cujo primogênito é Bom Senso. Desse nasceu Engenho (Wit) que se casou com Hilaridade (Mirth). Filho do Engenho com a Hilaridade, o temperamento do Verdadeiro Humor é ambíguo. Isso se reflete tanto em seu comportamento quanto em sua vestimenta, pois ora assume ares de seriedade e veste o manto negro do melancólico; ora é brincalhão, de trajes extravagantes e coloridos do louco do carnaval. Sejam quais forem suas vestes ou seu temperamento dominante, ele sempre desperta o riso no convívio social. Falso Humor é um impostor. Ele se assemelha ao Verdadeiro Humor apenas para aqueles incapazes de distinguir o tom de suas risadas. Se Verdade é o patriarca do Verdadeiro Humor, Falsidade é o do Falso. Desse nasceu Absurdo (Nonsense), cujo filho, Frenesi (Frenzy), casou-se com Risada (Laughter), uma das filhas da Tolice (Folly). Assim, o riso do Falso Humor é "alto e excessivo, donde raramente outros juntam-se a ele na risada” (ADDISON; STEELE, 1982, p. 335). Dessa história alegórica, gostaríamos de ressaltar a junção entre riso e seriedade: "Se o Verdadeiro Humor geralmente parece sério, todos riem com ele" (ADDISON; STEELE, 1982, p. 335).

Dissemos acima que Dépret classifica Lamb de o típico humorista inglês. Em History of English Humour, ao qual Dépret dedica uma seção do prefácio, L'Estrange procura estabelecer as condições do humor a partir de suas relações com o lúdico, o riso e a sátira. Em estudo exaustivo sobre o tema, $\mathrm{o}$ autor recorre às bases retóricas da literatura greco-romana, bem como às suas diferenças com o humor hebraico, para aportar na Inglaterra medieval. Contudo, diz Dépret, o estudo de L'Estrange se ocupa mais de um tipo social do que de uma forma literária, e a conclusão a que chega, de que o humor está ancorado no riso, dificilmente estabeleceria os perímetros entre o humor e as outras formas cômicas, como a sátira. Assim, Dépret contrasta a formulação

\footnotetext{
${ }^{5}$ É digno de nota, como observou Paul Dixon, que "a orelha aparece oito vezes" nas Memórias póstumas (DIXON, 2009, p. 36).
} 
de L'Estrange às de dois de seus conterrâneos, Edmund Scherer (1815-1889) e Paul Stapfer (1840-1917). ${ }^{6}$ Se o humor foi por muito tempo ignorado entre os franceses, ele passou a ser estudado na França a partir da segunda metade do século XIX, enquanto "gênero literário", "produto da pena", pois "nós [franceses] vemos a coisa como um temperamento literário" (DÉPRET, 1880, p. 34). O estudo de Scherer, Laurence Sterne ou l'Humoriste, atribui as origens do humor às contradições ou aos desacordos entre os personagens e o mundo. Stapfer, que empreendeu um estudo comparativo entre Shakespeare e Molière, estabelece três elementos essenciais do humor: o sentimento do risível, certa impressão de nulidade e o culto da desonra. Somam-se a eles, segundo Dépret, "a reabilitação e o amor pelo grotesco" (DÉPRET, 1880, p. 38).

Estaremos aqui no reino da sátira? Sim e não. Que há elementos satíricos nos Ensaios de Elia, e decerto no ensaio de periódico inglês dos séculos XVIII e XIX, é inegável, sobretudo da sátira menipeia. Sua realização perfeita são as sátiras de Luciano de Samósata (séc. II), cujas características básicas foram devidamente estabelecidas por um machadiano de peso, José Guilherme Merquior: ausência de distanciamento enobrecedor na figuração das personagens e ações; mistura do sério e do cômico; liberdade do texto em relação aos ditames da verossimilhança; representação literária de estados psíquicos aberrantes; e o uso constante de gêneros intercalados (MERQUIOR, 1972, p. 13-14). O próprio Luciano é vez ou outra evocado por Elia. Ainda mais recorrente são as alusões a Robert Burton, cujo “Prefácio satírico' [de Anatomia da melancolia] tem todo o aspecto formal desse gênero literário que era a sátira menipeia" (STAROBINSKI, 2012, p. 150).7

De Burton a Lamb a filiação é direta. Antes de Elia, em "On The Melancholy of Tailors", Lamb assumiu a persona de Burton Junior, referência explícita a Democritus Junior, a máscara pseudonímica no exórdio da Anatomia da melancolia. Além da mudança de humor, do disfarce humorístico, da erudição exuberante e da franqueza sem peias, Lamb empenhou-se em imitar o estilo de Burton. Imitação tão cerrada que, nos dizeres de William Hazlitt, quase anula a ideia de imitação (HAZLITT, 1998, p. 219). Burton e Lamb podem transitar e frequentemente transitam pela sátira. Mas o que se sobressai em seus livros é a presença de uma voz única,

\footnotetext{
${ }^{6}$ Coincidentemente ou não, em Machado de Assis: estudo comparativo de literatura brasileira, Sílvio Romero se apropria das teorias de Stapfer e Scherer em sua leitura do humor machadiano (1992, p. 169-175).

${ }^{7}$ Também sobre o tema, ver "Robert Burton e a Anatomia da melancolia". In: Enylton de Sá Rego, $O$ calundu e a panaceia: Machado de Assis, a sátira menipeia e a tradição luciânica, 1989, p. 76-80.
} 
subjetiva, opinativa e "o ato de cronicar as desilusões na escrita ou de transferi-las da mente ao texto" (HULL, 2018, p. 2). O resultado final, segundo a interpretação de Simon Hull, é o retrato nu e cru de uma figura ou de um tipo psíquico e sociologicamente determinável, isto é, o ensaísta.

O humorista típico é, pois, um observador irônico e um contador de histórias que oscila entre a pilhéria e a seriedade, sem que o leitor jamais possa definir se o leva a sério ou não, se ri ou se chora junto a ele. Filho do Engenho com a Hilaridade, ele é um ser eminentemente ambíguo, flexível; em suma, um ensaísta: um tipo literário que, com sua têmpora meditativa, desliza de uma impressão a outra, pula de pensamento em pensamento e, em meio a essa dispersão idiossincrática, cria "um mundo todo coeso" (OZICK, 2018, p. 230).

De volta a Dépret, o típico humorista é “o mais sensível dos homens”, "ainda mais sensível à descoberta da menor violação das leis do equilíbrio no mundo ao seu redor”. A sensibilidade permite-lhe perceber o que há de cômico no grave e solene, sem ceder às durezas da caricatura. Olha para si mesmo e ao redor com as lentes da análise e do sentimento pessoal. O humorista é aquele "que vem, a propósito de tudo, testemunhar em nome e pela humanidade” (DÉPRET, 1880, p. 39-41). Em linhas muito próximas a essas, Lúcia Miguel Pereira descreve a "atitude humorista" de Machado "pelo equilíbrio que confere" e por se colocar "simultaneamente próximo e distante do observado [...]. Humorista é, afinal, quem corrige uns pelos outros os excessos da simpatia e da crítica” (MIGUEL PEREIRA, 2015, p. 73). Entretanto, se dermos crédito a Dépret - que nos diz que “é impossível definir o humor, não apenas segundo uma exatidão científica, mas segundo uma única fórmula, por mais vaga e elástica que seja" (DÉPRET, 1880, p. 14) - ou mesmo a Alcides Maya, para quem o "[humour] não constitui critério de escola, não representa, sequer, um gênero de regras fixas” (MAYA, 2007, p. 13), como detalhar a linhagem a que Lamb pertenceu?

Em "Coup d'oeil sur les prédécesseurs de Charles Lamb", um dos tópicos do prefácio de Dépret, diz o autor: “Os predecessores de Charles Lamb [...] chamam-se Addison, Swift, Steele e Johnson. Indicar as fases que atravessam a literatura inglesa, de Addison a Lamb, é contar uma genealogia literária” (DÉPRET, 1880, p. 44). Ora, os autores pertencentes a essa genealogia literária, tendo Addison à frente, destacaram-se no ensaio de periódico. Por mais dissimilares que sejam suas afinidades físicas e morais - Swift é "uma figura antipática"; Johnson, um "ditador da literatura inglesa"; Goldsmith, outro nome acrescido ao capítulo, autor de "sentimento e estilo" -, todos 
escreveram sob o signo de Addison. Foi no ocaso dessa genealogia, diz Dépret, “que nasceu Charles Lamb” (DÉPRET, 1880, p. 46, 48-49 e 51).

Depois de algumas tentativas frustradas com sonetos, peças teatrais e a narrativa $A$ tale of Rosamund Gray, Lamb se revelou um exímio contador de histórias em Contos de Shakespeare, obra escrita a quatro mãos, entre ele e a irmã, Mary. Mas é no tom exato e na medida precisa entre poesia e prosa de seus ensaios de periódicos que encontramos o Lamb humorista, a sua melancolia espirituosa [wit-melancholy]. ${ }^{8}$ Desses ensaios, os mais conhecidos, os mais egotísticos e autobiográficos são, sem sombra de dúvidas, os Ensaios de Elia.

Os Ensaios de Elia são quase coevos à criação do London Magazine, onde foram inicialmente publicados. O objetivo central do magazine era "traduzir em uma miscelânea vívida o dinamismo e o tumulto da vida londrina" (HULL, 2010, p. 2). A parceria de Lamb com London "foi pronta e decisiva", diz Dépret (1880, p. 113). Ainda segundo o crítico, ao se imiscuir no tumulto da cidade moderna, Lamb reatualizava a veia original, o estilo e as observações agudas dos tempos de Steele e Addison, ao mesmo tempo em que abria caminho para autores como Dickens, o qual, em Sketches by Boz, assumiu-se também como escritor metropolitano e se inseriu na extensa genealogia de ensaístas e humoristas. A observação é tanto mais interessante pois está de par com as pesquisas mais recentes sobre o ensaísmo inglês. ${ }^{9}$ Contudo, há uma diferença substancial quanto ao tema dos Ensaios de Elia e aquele de qualquer outra miscelânea de ensaios existente até então. Nenhuma se pretendeu como apaixonante documento da história de vida do autor, ainda que sob a persona de Elia, da infância à velhice.

Dépret encerra o prefácio com uma lista das obras de Lamb que consultou. Foram cinco as edições de suas obras de 1818 a 1875. A mais completa e a primeira a reunir as colaborações de Lamb com Mary é a edição centenária de Charles Kent, 1875. Se Lamb cairia em descrédito no entreguerras, este certamente não era o caso na década de 1880. Por intermédio de Dépret, das intensas relações comerciais e culturais entre França e Brasil e da livraria Garnier, um exemplar de Lamb foi parar nas mãos de um escritor que de bate-pronto reconheceu suas "afinidades estéticas" Machado de Assis (GUIMARÃES, 2008, p. 42). Ainda que não possamos responder o porquê de Machado ter incluído o nome de um ensaísta no prólogo de um romance, espero, com este artigo, ter explicitado as relações da

${ }^{8}$ A expressão é de Leigh Hunt, que traçou um perfil do autor em 1851. Ver Leigh Hunt, Selected Writings, 2003, p. 93.

${ }^{9}$ Ver Gregory Dart, Metropolitan Art and Literature, 2012. 
linha humorística dos Ensaios de Elia e das Memórias póstumas. Se admitirmos que Machado estudou o amplo aparato crítico de Essais Choisis, por intermédio dele o escritor brasileiro pôde aprofundar seu conhecimento do humor inglês e compreender Lamb, nas palavras de Dépret, como "ensaísta da linhagem dos melhores que já se viu na Inglaterra” (1880, p. 120), enquanto inovador da forma e autor de um tipo de humor no qual riso e melancolia são inseparáveis.

\section{Referências}

ADDISON, Joseph; STEELE, Richard. Selections from The Tatler and The Spectator. Edição, introdução e notas de Angus Ross. Londres: Penguin Books, 1982.

ASSIS, Machado de. Memórias póstumas de Brás Cubas. Rio de Janeiro: Tipografia Nacional, 1881.

. Obra completa. São Paulo: Nova Aguiar, 2015. v. 1.

BACON, Francis. Complete Essays. Introdução de Oliphant Smeaton. Mineola; New York: Dover Publications, 2008.

DART, Gregory. Metropolitan Art and Literature: 1810-1840, Cockney Adventures. Cambridge: Cambridge University Press, 2012.

DÉPRET, Louis. Préface. In: LAMB, Charles. Essais Choisis: précédés d'une etude sur l'humour et d'une notice littéraire sur Charles Lamb. Trad. Louis Dépret. Paris: G. Charpentier, Libraire-Éditeur, 1880.

DIXON, Paul. O chocalho de Brás Cubas: uma leitura das Memórias póstumas. São Paulo: Edusp; Nankin, 2009.

GUIMARÃES, Hélio de Seixas. Machado de Assis e o paradigma inglês. In: Machado de Assis: novas perspectivas sobre a obra e o autor, no centenário de sua morte. Organização de Antonio Carlos Secchin, Dau Bastos e José Luís Jobim. Rio de Janeiro: EdUff, 2008. p. 35-45.

. Machado de Assis: o escritor que nos lê. São Paulo: Editora Unesp, 2017.

HAZLITT, William. The Selected Writings of William Hazlitt. Editado por Duncan Wu. Londres: Pickering \& Chatto, 1998. v. 6.

HIGGINS, David. Romantic Englishness: Local, National and Global Selves, 17801850. Basingstoke: Palgrave Macmillan, 2014.

HULL, Simon Peter. Charles Lamb, Elia and The London Magazine. London: Routledge, 2010.

. The Familiar Essay, Romantic Affect and Metropolitan Culture: the sweet security of streets. Newcastle: Cambridge Scholars Publishing, 2018.

HUNT, Leigh. Selected Writings. Editado por David Jesson-Dibley. Exeter: FyfieldBooks, 2003. 
JOBIM, José Luís. A biblioteca de Machado de Assis. Organização de José Luís Jobim. Rio de Janeiro: Academia Brasileira de Letras; Topbooks, 2001.

JOURNAL DES DÉBATS. <gallica.bnf.fr>. Bibliothèque Nationale de France. 19 jul. 1880. Disponível em: <https://gallica.bnf.fr/ark:/12148/bpt6k4612263.item>. Acesso em: 28 fev. 2021 (s.p.).

LAMB, Charles. The Works of Charles Lamb. Londres: Edward Moxon; Dover Street, 1850. v. II.

. Essais Choisis: précédés d'une etude sur l'humour et d'une notice littéraire sur Charles Lamb. Trad. Louis Dépret. Paris: G. Charpentier, Libraire-Éditeur, 1880 .

Elia \& The Last Essays of Elia. Editado por Jonathan Bate. Oxford: Oxford University Press, 1987.

. Selected Prose. Editado por Adam Phillips. London: Penguin Books, 2013.

LOCKE, John. Ensaio sobre o entendimento humano. Trad. Pedro Paulo Garrido Pimenta. São Paulo: Martins Fontes, 2012.

MACDONALD, W.L. Charles Lamb, the Greatest of the Essayists. PMLA, v. 32, n. 4, 1917. p. 557-572.

MAYA, Alcides. Machado de Assis: algumas notas sobre o humour. Santa Maria: Editora UFSM, 2007.

MIGUEL PEREIRA, Lúcia. Prosa de ficção. In: ASSIS, Machado de. Obra completa. São Paulo: Nova Aguiar, 2015. v. 1. p. 66-76.

MERQUIOR, José Guilherme. Gênero e estilo das Memórias póstumas de Brás Cubas. Colóquio Letras, n. 8., p. 12-20, jul. 1972. Fundação Calouste Gulbenkian. Disponível em:

http://coloquio.gulbenkian.pt/cat/sirius.exe/issueContentDisplay?n=8\&p=12 $\& \mathrm{o}=\mathrm{p}>$. Acesso em: Acesso em: 31 jan. 2021 . p. 12-20.

OZICK, Cynthia. O retrato do ensaio como corpo de mulher. In: Doze ensaios sobre o ensaio. Antologia Serrote. Organização de Paulo Roberto Pires. São Paulo: Instituto Moreira Salles, 2018. p. 46-59.

REGO, Enylton de Sá. O calundu e a panaceia: Machado de Assis, a sátira menipeia e a tradição luciânica. Rio de Janeiro: Forense Universitária, 1989.

RIEHL, Joseph E. That Dangerous Figure: Charles Lamb and the critics. Rochester: Camden House, 1998.

ROMERO, Sílvio. Machado de Assis: estudo comparativo de literatura brasileira. Campinas: Editora da Unicamp, 1992.

ROUANET, Sergio Paulo. Riso e Melancolia: a forma shandiana em Sterne, Diderot, Xavier de Maistre, Almeida Garret e Machado de Assis. São Paulo: Companhia das Letras, 2007.

SCHWARZ, Roberto. Um mestre na periferia do capitalismo: Machado de Assis. 5. ed. São Paulo: Duas Cidades; Editora 34, 2000.

STAROBINSKI, Jean. A tinta da melancolia: uma história cultural da tristeza. Trad. Rosa Freire d'Aguiar. São Paulo: Companhia das Letras, 2012. 
Machado de Assis em Linha - Universidade de São Paulo

http://machadodeassis.fflch.usp.br - Artigo

WOODBRIDGE JR., Benjamin Mather. Sir Thomas Browne, Lamb e Machado de Assis. Machado de Assis em Linha: revista eletrônica de estudos machadianos, São Paulo, v. 7, n. 13, p. 1-4, jun. 2014. Disponível em: $<$ http://machadodeassis.net/download/numerol3/artigo01.pdf >. Acesso em: 26 ago. 2020.

DANIEL LAGO MONTEIRO é doutor em Teoria Literária e Literatura Comparada pela Universidade de São Paulo, onde obteve bacharelado em História e mestrado em Filosofia. Foi pesquisador visitante na Universidade de Londres, Birkbeck College, e bolsista Fulbright em Rutgers, The State University of New Jersey. É autor do livro: No Limiar da Visão: a poética do sublime em Edmund Burke (LiberArs, 2018). Atualmente, realiza uma pesquisa de pós-doutorado, com bolsa da FAPESP, na Unicamp.

(1D) https://orcid.org/0000-0001-6520-087X E-mail: daniel.I.monteiro@hotmail.com

Recebido: 01.09.2020

Aprovado: 06.01.2021 